\title{
Methods for Installation, Removal, and Downloading Data from the Temperature Profiling Probe (TROD)
}

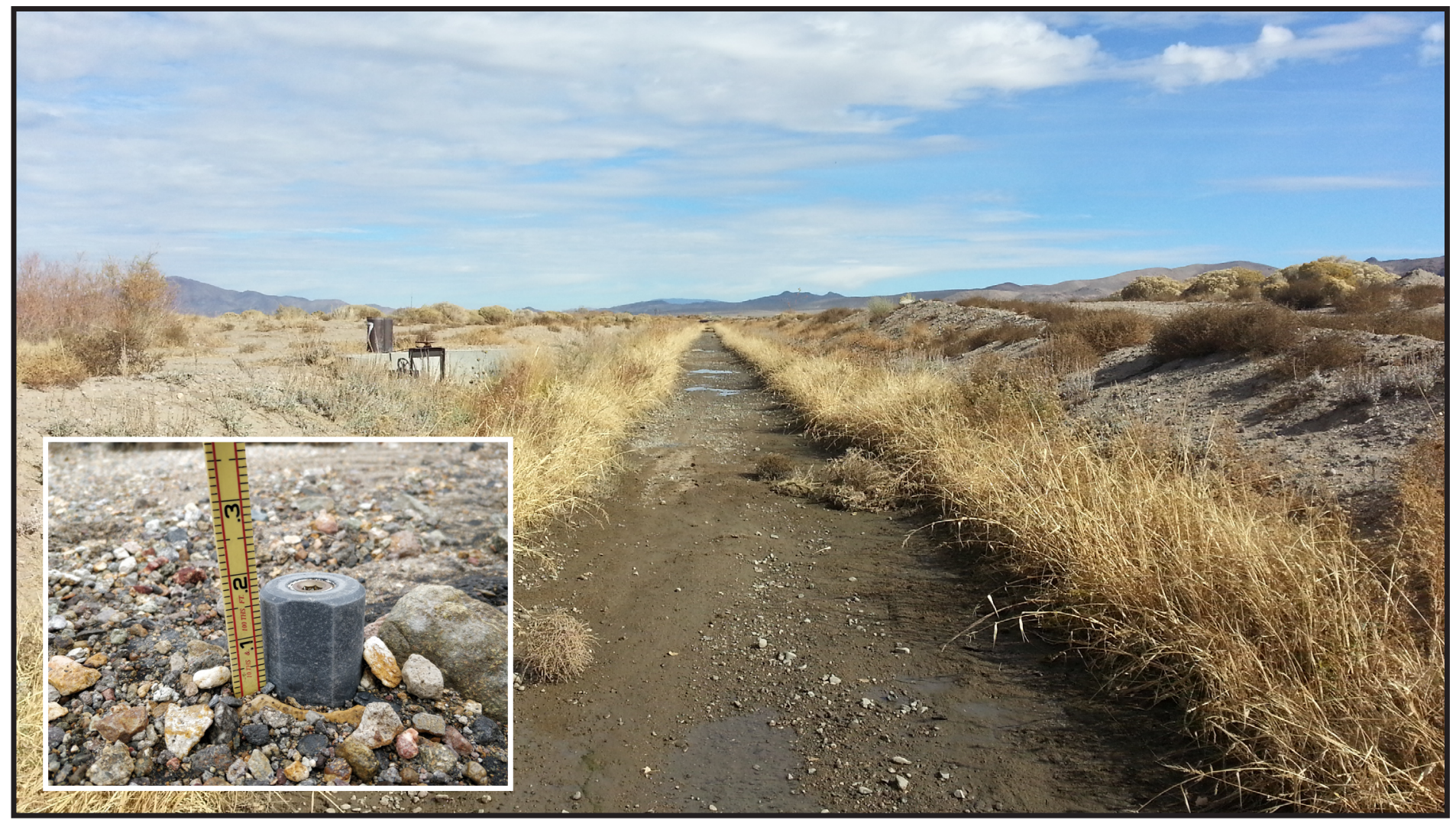

Open-File Report 2019-1066

U.S. Department of the Interior

U.S. Geological Survey 


\section{Cover photographs:}

Front: Main photograph: Downgradient view of the dry Saroni Canal, near Wellington, Nevada. Photograph by David Smith, 2013. Inset photograph: Close-up image of the stick up height of the temperature profiling probe (TROD). Photograph by David Smith, 2013.

Back: TROD installation. Photograph by David Smith, 2013. 


\section{Methods for Installation, Removal, and Downloading Data from the Temperature Profiling Probe (TROD)}

By Ramon C. Naranjo

Open-File Report 2019-1066 


\title{
U.S. Department of the Interior DAVID BERNHARDT, Secretary
}

\author{
U.S. Geological Survey \\ James F. Reilly II, Director
}

U.S. Geological Survey, Reston, Virginia: 2019

For more information on the USGS - the Federal source for science about the Earth, its natural and living resources, natural hazards, and the environment-visit https://www.usgs.gov or call 1-888-ASK-USGS.

For an overview of USGS information products, including maps, imagery, and publications, visit https://store.usgs.gov.

Any use of trade, firm, or product names is for descriptive purposes only and does not imply endorsement by the U.S. Government.

Although this information product, for the most part, is in the public domain, it also may contain copyrighted materials as noted in the text. Permission to reproduce copyrighted items must be secured from the copyright owner.

Suggested citation:

Naranjo, R.C., 2019, Methods for installation, removal, and downloading data from the temperature profiling probe (TROD): U.S. Geological Survey Open-File Report 2019-1066, 14 p., https://doi.org/10.3133/ofr20191066. 


\section{Contents}

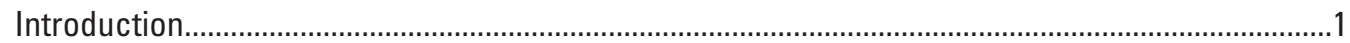

Common Type of Temperature Tracing Approaches.............................................................................1

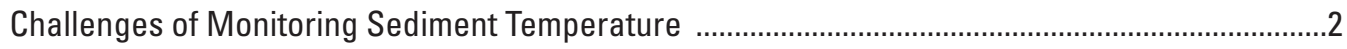

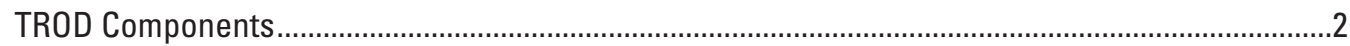

iButtons for Logging and Storage ...........................................................................................

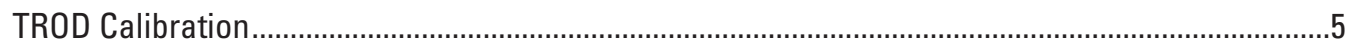

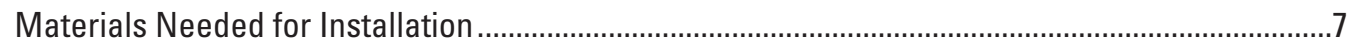

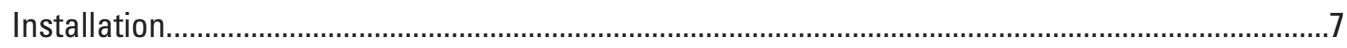

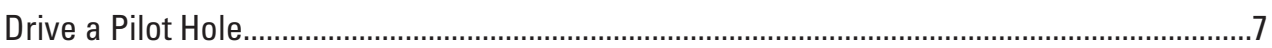

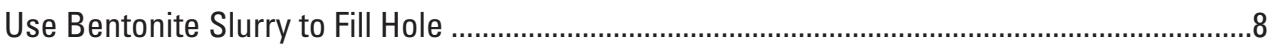

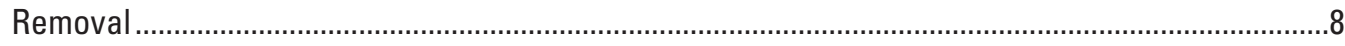

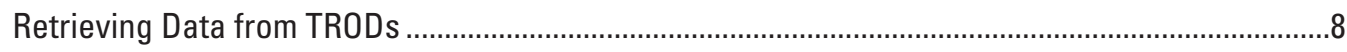

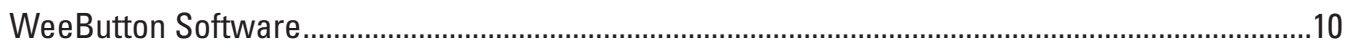

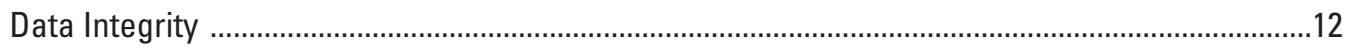

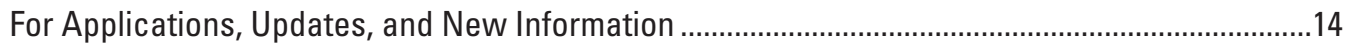

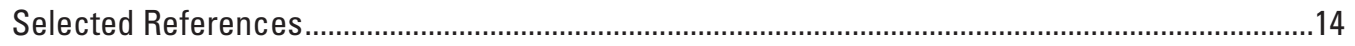

\section{Figures}

1. Illustration showing common type of temperature tracing approaches ...........................2

2. Photographs showing Campbell logger with thermocouple array, distributed temperature sensor, piezometer with temperature loggers installed inside, and TRODs installed in canal.

3. Images showing materials and components of the TROD include $3 / 4$ inch SCH 80 PVC housing with a solid PVC drive point and head, printed circuit board that have insulated foam around the iButtons, special clamp that connects to two bolts at the head TROD, and installation cap, communication cable, and extension bar.

4. Photograph showing aA TROD placed into a flow-through column or pipe with water circulating from a water bath for sensor calibration ...............................................5

5. Graphs showing TROD versus NIST thermometer............................................................

6. Photographs showing a completely installed TROD, installation cap, fence-post puller, extra-long pipe wrench, fence-post driver for installing rock bar used for pilot hole, and rock bar ...................................................................................................

7. Photograph showing the pilot hole is the most critical aspect to installing the TROD.....8

8. Photographs showing TROD with pilot hole, installed TROD into the bentonitefilled pilot hole, and use of an extension rod to drive the TROD in moving water .............9

9. Photographs showing TROD removed by digging in mud, or using a Prusik knot and a Hi-Lift jack .............................................................................................................

10. Image showing WeeButton software for retrieving data from TRODs..............................10

11. Image showing Step 1. Start WeeButton software for use with the temperature profiling probe ....................................................................................................................10

12. Image showing Step 2. Start programs for all iButtons at "Mission Start" ......................11

13. Image showing Step 3. Click on "iButton21" tab and set programs for all iButtons.......11 
14. Image showing Step 4. To download data, "Stop All" mission and then retrieve data by clicking on "Save All Rod"

15. Image showing Step 5. WeeButton raw output is provided by sorting the iButtons in order from top to bottom sensor in an Excel file

16. Graphs showing example data collected from a site with a properly sealed TROD, a site with a problematic install, and re-installed TROD.

\section{Table}

1. Characteristics of iButtons used for hydrological investigations

\section{Abbreviations}

USGS

TROD

FO-DTS

PCB

PVC

$\mathrm{SCH}$

NIST
U.S. Geological Survey

temperature profiling probe, SensorRod, or temperature rod

Fiber Optic Distributed Temperature Sensing

printed circuit board

polyvinyl chloride

schedule

National Institute of Standards and Technology 


\title{
Methods for Installation, Removal, and Downloading Data from the Temperature Profiling Probe (TROD)
}

\author{
By Ramon C. Naranjo
}

\section{Introduction}

This document provides a brief method overview on the deployment and removal of the temperature profiling probe developed by the U.S. Geological Survey (USGS) in 2015 and referred to as SensorRod or temperature rod (TROD). The TROD is suitable for short- to long-term deployments (days to years) for evaluating thermal gradients in soils and sediments beneath surface water. Applications include evaluating exchange between groundwater and surface water, seepage losses in agricultural canals, infiltration on hillslopes, and timing of snowmelt and runoff. The temperature sensors inside the TROD are iButtons and are meant to be replaceable when needed. The housing is water tight and is made of schedule 80 PVC pipe. Sensor intervals are flexible and can be built to specific applications.

A joint patent (U.S 10/180,360.) and license agreement between the USGS and Alpha Mach for the TROD design was obtained in 2019, and a paper in Water Resource Research describes the design and testing (Naranjo and Turcotte, 2015).

\section{Common Type of Temperature Tracing Approaches}

There are many monitoring approaches for collecting water and sediment temperatures (fig. 1). In a surface water system, this includes the use of a $(A)$ piezometer,
$(B)$ thermocouple array, or $(C)$ fiber optic distributed temperature sensor (FO-DTS), and $(D)$ the subsurface temperature profiling probe (TROD). Deployment of temperature sensors using $A-C$ are limited to shallow depths and can be susceptible to damage at high stage from increased velocity or debris, whereas the TROD is nonobstructive to flow, thus allowing for installation in a variety of environments. Data are obtained from the piezometer by removing all temperature sensors from the piezometer and connecting to each sensor to obtain data individually. This results in multiple datasets or files representing temperature observations within the piezometer. In contrast, data are retrieved from the TROD through the 25 -foot submersible communication cable or by direct contact with the head of the probe, and temperature measurements are read for all sensors simultaneously and stored as one dataset. The communication cable can also be buried into sediments and directed to a location where downloading data is more accessible or efficient.

The TROD largely overcomes the limitations of other equipment used for measuring environmental temperatures, especially in stream environments. The main advantages are (1) the low-profile design allows for continuous monitoring in harsh environments that are susceptible to floating debris, high velocities, or high stage; (2) it does not require removal or disruption for data retrieval; (3) it uses low-cost, existing self-logging temperature sensors that are easily replaced and allows prolonged use of the bulk of materials; and (4) software developed specifically for the TROD is easy to use and efficient in programing and downloading data. 


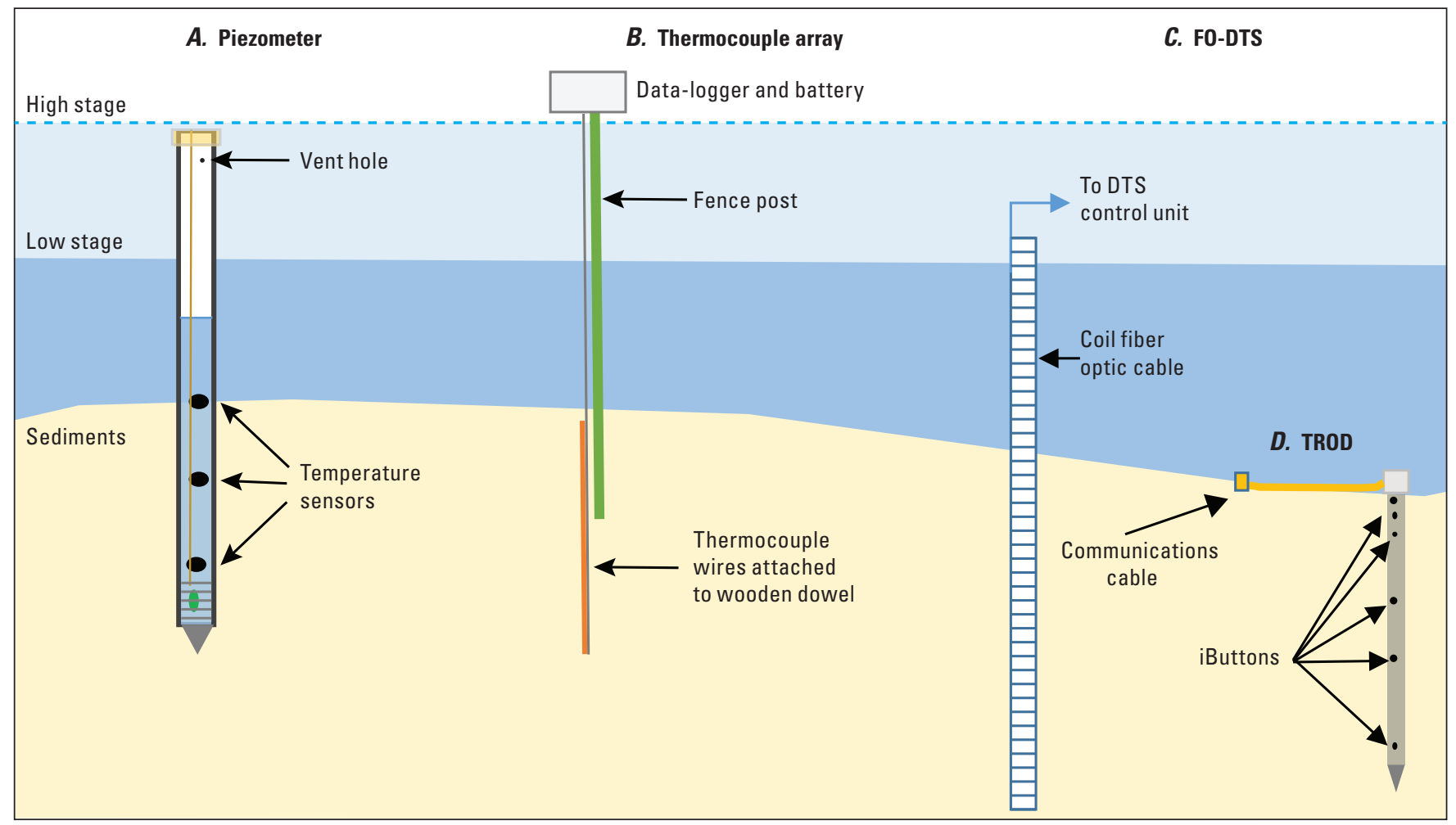

Naranjo and Turotte (2015)

Figure 1. Common type of temperature tracing approaches: $A$, piezometer; $B$, thermocouple array; $C$, FO-DTS; and $D$, TROD (adopted from Naranjo and Turcotte, 2015). The dashed line indicates high stage conditions with water submerging the top of the piezometer.

\section{Challenges of Monitoring Sediment Temperature}

Measuring and recording temperature with handheld devices is generally easy and inexpensive. However, measuring continuous temperature in dynamic environments, such as perennial or ephemeral streams, can pose major practical challenges. For example, floating debris during runoff can cause problems with shifts in sensor spacing, anomalous readings, and in extreme cases, destruction of equipment (fig. 2).

A temperature probe that is low profile has many advantages over these traditional systems. For example, with minimal stick up, the TROD avoids the issues with debris that can occur with piezometers, thermal couple temperature arrays, or fiber optic DTS deployments. An installed TROD is also low profile and can be deployed in environments where vandalism may be a problem. Data are also retrieved as one dataset without disruption to the sensors. This eliminates the issue of erroneous data that would be caused by the act of removing and replacing sensors while recording continuous data. Data are also stored on individual sensors using selfcontained memory and batteries.

\section{TROD Components}

The iButtons are enclosed $(A)$ in a $3 / 4$-inch schedule (SCH) 80 PVC housing with a solid PVC drive point and head (fig. 3). The communication cable is connected to a $(B)$ printed circuit board (PCB) that has insulated foam around the iButtons. At each clip, the iButtons can be removed without special tools for replacement as battery life becomes depleted. The installation cap serves to prevent damage to the head bolt and to the cable while hammering. An extension bar can be inserted into the installation cap to drive the TROD into sediments in environments beneath surface water. Data are downloaded with the use of a USB cable and adaptor connected to a water-resistant connection at the end of the communication cable or with the use of $(C)$ a special clamp that connects to two bolts at the head TROD (without communication cable). The TROD without a communication cable $(D)$ was designed for use in environments where visibility and vandalism may be an issue. The extension bar (also shown in $D$ ) used to drive the TROD into the subsurface is made of a repurposed hardened steel grounding rod with a stainless-steel bolt, nut, and washer to prevent the rod from passing through the installation cap when applying force.

The spacing of the temperature sensors inside the TROD can be designed at a minimal interval spacing of 5 centimeters (cm). Typical lengths of the TROD are 0.5 to 1 meter (m). Longer or shorter lengths can be special ordered. 
A. Campbell logger with thermocouple array

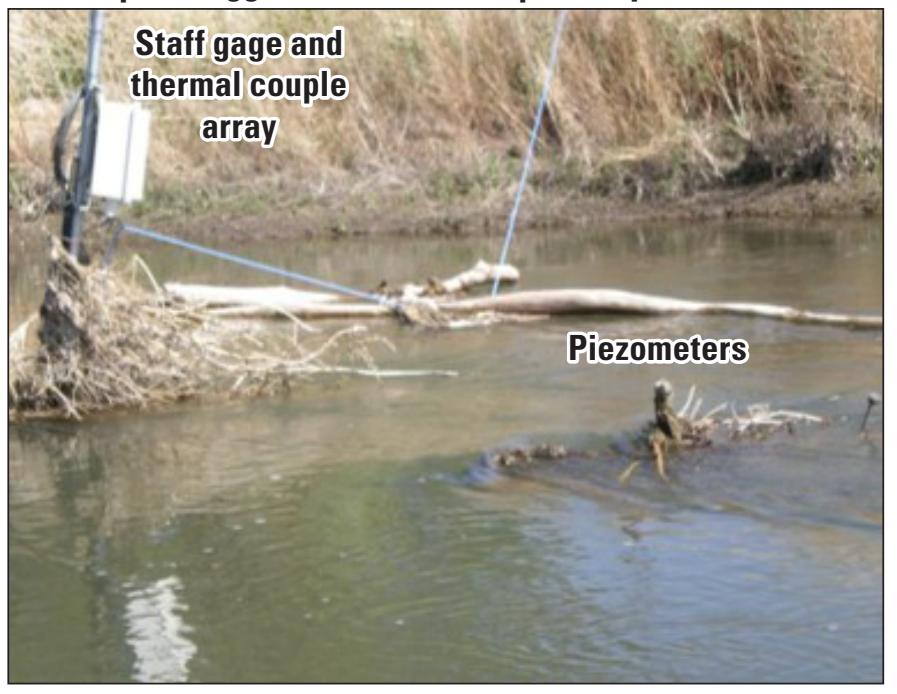

\section{Piezometer with temperature loggers installed inside}

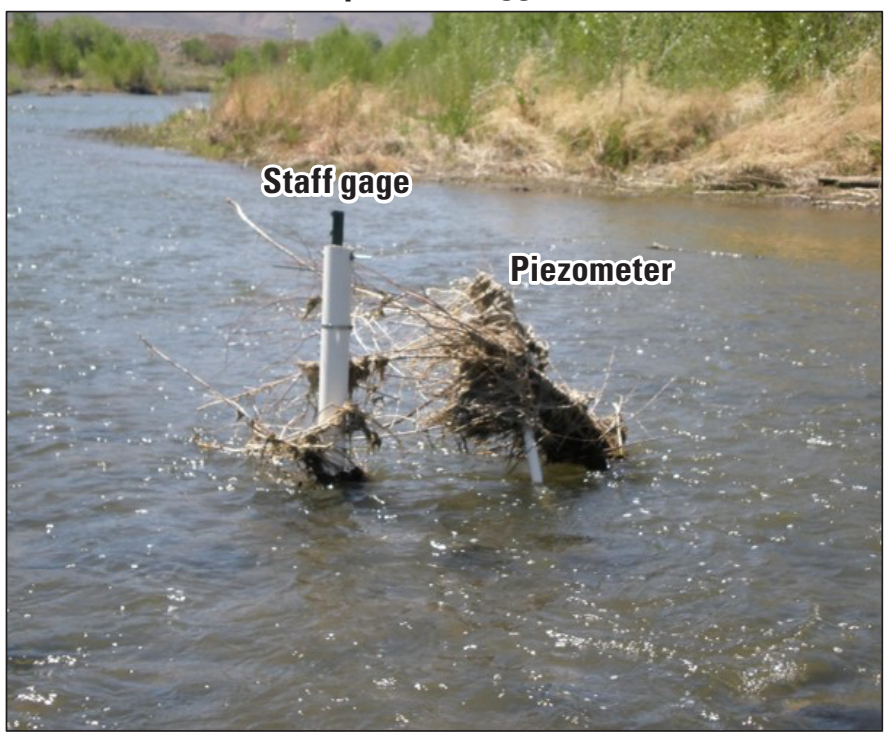

\section{B. Distributed temperature sensor (DTS)}

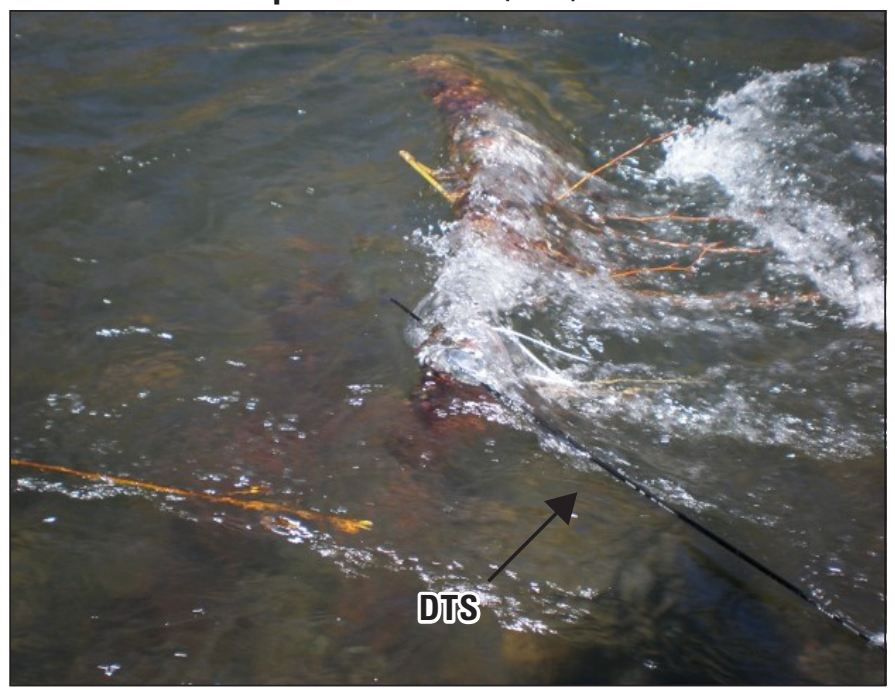

\section{TRODs installed in canal}

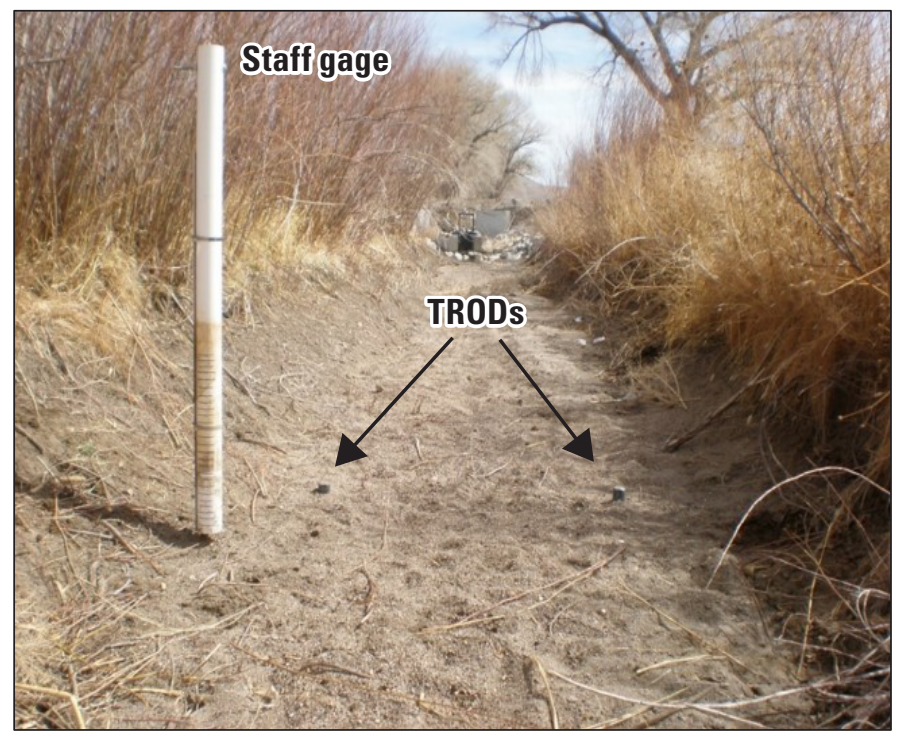

Figure 2. A, Campbell logger with thermocouple array; $B$, distributed temperature sensor (DTS); $C$, piezometer with temperature loggers installed inside; and $D$, TRODs installed in canal. Photos $(A-C)$ illustrate the challenges in monitoring sediment temperature in natural environments. Given the low-profile design of the $\operatorname{TROD}(D)$, the potential risk of damage to instrumentation is reduced. 


\section{TROD Components}

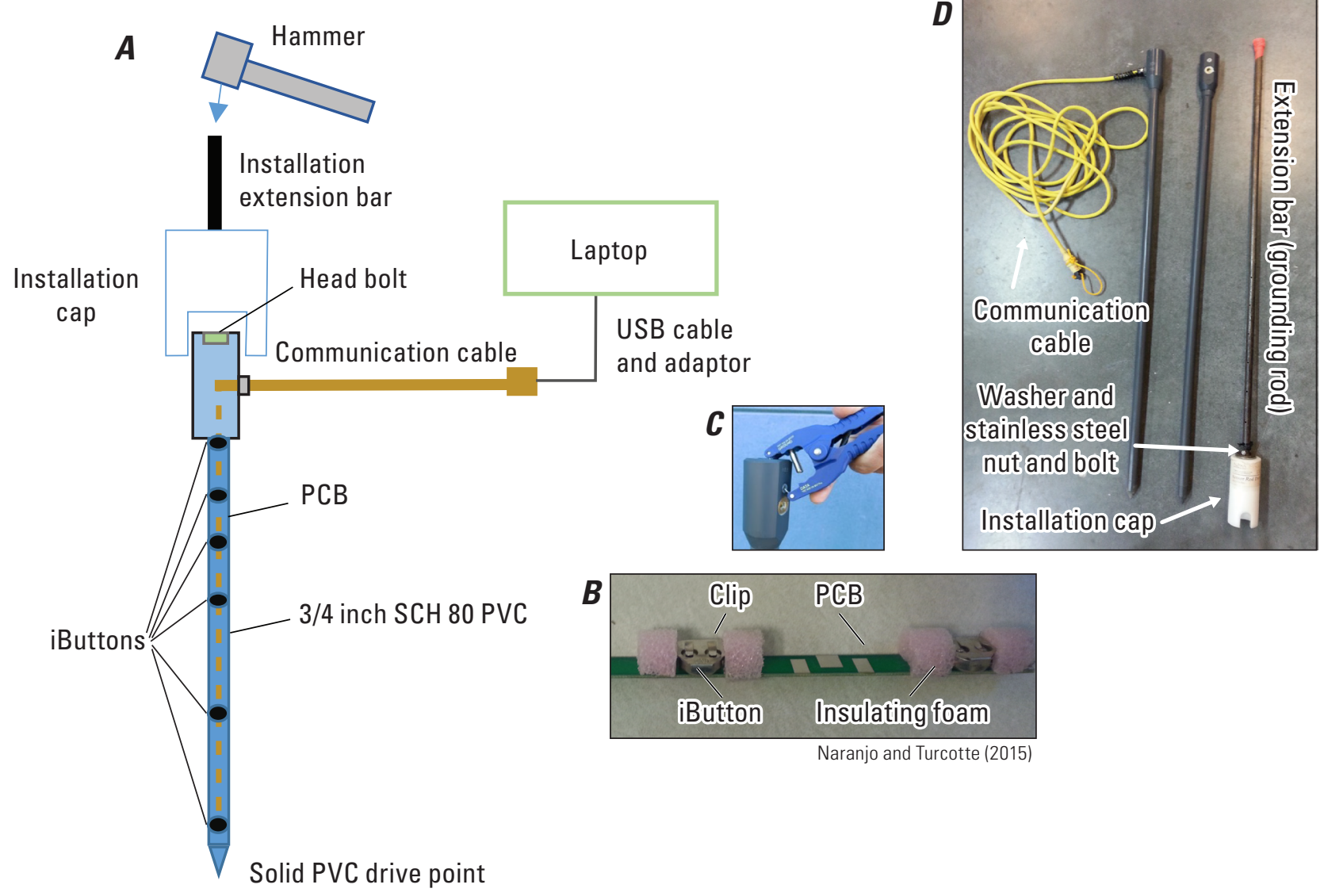

Figure 3. Materials and components of the TROD include $A, 3 / 4$ inch SCH 80 PVC housing with a solid PVC drive point and head; $B$, printed circuit board (PCB) that have insulated foam around the iButtons; $C$, special clamp that connects to two bolts at the head TROD (without communication cable); and $D$, installation cap, communication cable, and extension bar.

\section{iButtons for Logging and Storage}

About the size of a nickel, the iButton temperature sensors are very easy to use and inexpensive compared to other options commercially available. By themselves, iButtons are not waterproof and must be housed in a watertight enclosure to prevent failure. There are many choices of sensors for the TROD that vary in cost, accuracy, precision, and data storage capability (table 1).

The most commonly used sensors in hydrologic investigations are Type Z (DS1921Z) and Type L (DS1922L). However, the amount of data and the resolution are the biggest differences between Types $\mathrm{Z}$ and L. Type $\mathrm{Z}$ can store 4,096 readings, whereas Type $L$ can store 8,192 readings. The resolution is also better with Type $\mathrm{L}\left(0.0625^{\circ} \mathrm{C}\right)$ than Type $\mathrm{Z}$ $\left(0.125^{\circ} \mathrm{C}\right)$. Keep in mind the resolution and temperature range available for different iButtons (table 1) and what is needed for site specific applications. The resolution and temperature range are important considerations that need to be resolved for site specific applications.

The finer resolution on the Type $\mathrm{L}\left(0.0625^{\circ} \mathrm{C}\right)$ must be specified in the software because the default resolution defined by the manufacture is $0.5^{\circ} \mathrm{C}$. New sensors (DS1925L) have the capability to expand the logging capabilities of the TROD and minimize the frequency of required downloads. New sensors released by the manufacturer can provide new opportunities for longer deployments and improved resolution (DS-1925L-F5). 
Table 1. Characteristics of iButtons used for hydrological investigations.

[hrs, hours; KB, kilobyte; mins, minutes; ${ }^{\circ} \mathrm{C}$, degree Celsius; \pm , plus or minus]

\begin{tabular}{|c|c|c|c|c|c|}
\hline Model & Temperature range & Accuracy & Resolution & Values/readings & Logging rate \\
\hline DS1921G-F5\# & $-40{ }^{\circ} \mathrm{C}$ to $+85^{\circ} \mathrm{C}$ & $\begin{array}{l} \pm 1.0^{\circ} \mathrm{C}\left(-30 \text { to }+70{ }^{\circ} \mathrm{C}\right) \\
\pm 1.3{ }^{\circ} \mathrm{C} \text { full scale }\end{array}$ & $0.5^{\circ} \mathrm{C}$ & $2 \mathrm{~KB}$ & 1 to $255 \mathrm{mins}$ \\
\hline DS1921Z-F5\# & $-5^{\circ} \mathrm{C}$ to $26^{\circ} \mathrm{C}$ & $\pm 1.0^{\circ} \mathrm{C}$ full scale & $0.125^{\circ} \mathrm{C}$ & $2 \mathrm{~KB}$ & 1 to $255 \mathrm{mins}$ \\
\hline DS1922E-F5\# & $15^{\circ} \mathrm{C}$ to $140^{\circ} \mathrm{C}$ & $\begin{array}{l} \pm 1.5^{\circ} \mathrm{C}\left(+110 \text { to }+140{ }^{\circ} \mathrm{C}\right) \\
\pm 7{ }^{\circ} \mathrm{C} \text { full scale }\end{array}$ & $\begin{array}{l}0.5^{\circ} \mathrm{C}-8 \text { bit } \\
0.0625^{\circ} \mathrm{C}-11 \text { bit }\end{array}$ & $8 \mathrm{~KB}$ & $1 \mathrm{sec}$ to $273 \mathrm{hrs}$ \\
\hline DS1922T-F5\# & $0{ }^{\circ} \mathrm{C}$ to $125^{\circ} \mathrm{C}$ & $\begin{array}{l} \pm 0.5^{\circ} \mathrm{C}\left(+20 \text { to }+75^{\circ} \mathrm{C}\right) \\
\pm 2.1^{\circ} \mathrm{C} \text { full scale }\end{array}$ & $\begin{array}{l}0.5^{\circ} \mathrm{C}-8 \text { bit } \\
0.0625^{\circ} \mathrm{C}-11 \text { bit }\end{array}$ & $8 \mathrm{~KB}$ & $1 \mathrm{sec}$ to $273 \mathrm{hrs}$ \\
\hline DS1925L-F5\# & $-40{ }^{\circ} \mathrm{C}$ to $+85^{\circ} \mathrm{C}$ & $\pm 0.5^{\circ} \mathrm{C}$ full scale & $\begin{array}{l}0.5^{\circ} \mathrm{C}-8 \text { bit } \\
0.0625^{\circ} \mathrm{C}-11 \text { bit }\end{array}$ & $122 \mathrm{~KB}$ & 5 mins to $273 \mathrm{hrs}$ \\
\hline
\end{tabular}

\section{TROD Calibration}

The purpose of calibration is to improve precision and minimize error of temperature readings. Commonly, this is achieved by comparing temperature sensors to an independent device and correcting readings through linear regression analysis. For the TROD, it is necessary to submerge the entire assembly into a water bath and allow adequate time for the materials to arrive at equilibrium with the bath temperatures. The materials needed to calibrate the TROD are shown in figure 4. During the calibration process, it is necessary to set the TROD to record at a minimum 5-minute interval when placed into a flow-through column or pipe with water circulating from a water bath. Water is then circulated around the TROD using a submersible pump inserted into the water bath with a valve at the bottom to control the flow into a 4-inch pipe. Water is pumped into the flow-through tube near the bottom and flows out the top back into the water bath to keep the water circulating and a consistent temperature. For each sensor, a regression equation is developed to correct raw data based on points ranging from 5 to $25^{\circ} \mathrm{C}$. The independent device used to correct the TROD data is a National Institute of Standards and Technology (NIST)-certified traceable digital thermometer (Cat 4000, Control Company), with resolution $0.0001{ }^{\circ} \mathrm{C}$ and accuracy $0.05^{\circ} \mathrm{C}$, placed near the center of the pipe to obtain measurements as close to all sensors as possible. A total of six individual regressions developed for each iButton allow for the correction of data downloaded from the TROD using a more precise temperature device (fig. 5). Guidelines for calibration of temperature sensors by the USGS require an annual five-point calibration using a temperaturecontrolled water bath and NIST-traceable thermometer (Wagner and others, 2006).

Figure 4. A TROD placed into a flow-through column or pipe with water circulating from a water bath for sensor calibration.

\section{Flow-through column}

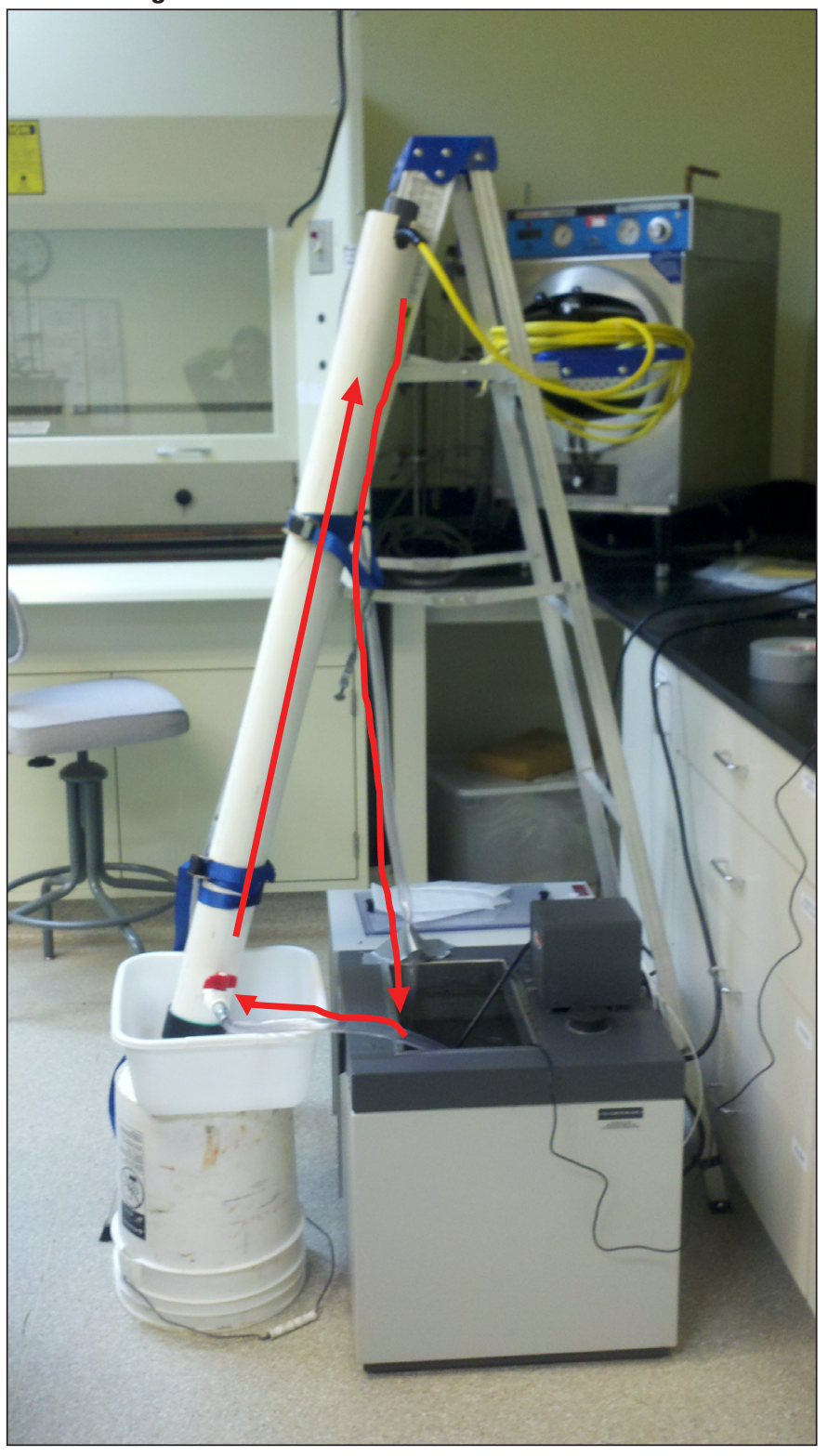


TROD versus NIST thermometer
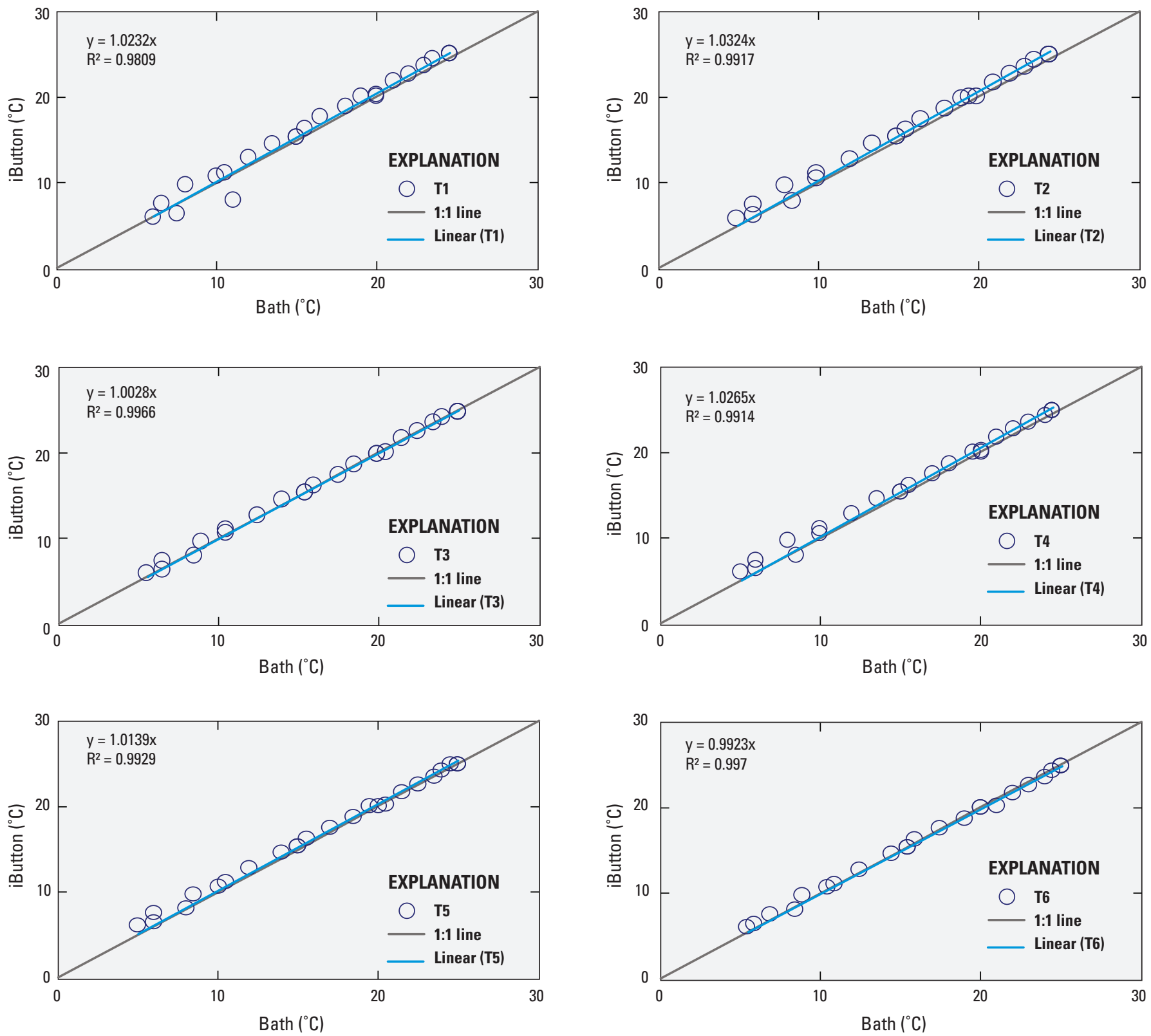

Figure 5. TROD versus NIST thermometer [USGS policy on calibration of temperature loggers at https://pubs.usgs.gov/tm/2006/tm1D3/ pdf/TM1D3.pdf]. For demonstration purposes, plots show calibration using 22 calibration points rather than minimum recommendation of 5 .

A common issue with calibrating sensors is not maintaining stable temperatures in the water bath and not allowing enough time for the materials to achieve equilibrium with the water bath temperature. It is important to monitor bath temperatures within the flow-through column and minimize variation in the bath temperatures while obtaining temperature values for calibration. Allowing the water bath and the TROD to reach equilibrium at each target temperature is also important. At least 20 minutes are needed to ensure the PVC materials has achieved equilibrium with the water bath. Measuring bath temperatures over a period of 10 minutes for each target temperature will also provide assurance that the bath temperatures are stable. 


\section{Materials Needed for Installation}

Installing a TROD into channel sediments can be challenging and time consuming in environments with cobbles or clay deposits beneath the surface. It is also imperative that the TROD is completely sealed from preferential flow vertically along the sides. Sediments will collapse around the pipe; however, there are occasions where an ineffective seal may result in preferential flow vertically down the pipe resulting in erroneous data. Installation can be accomplished with hand tools with common materials shown in figure 6 . Protection of the cable may be needed in situations where damage from animals to the cable is possible (fig. $6 G$ ). Digging a trench and burying the communication cable will also protect from floating debris.

\section{Installation}

\section{Drive a Pilot Hole}

Care must be taken when installing the TROD to prevent damage. The TROD is very sturdy and is designed to be hammered into the ground, but it must first be proven (using solid steel) that it is possible to obtain the desired depth. A pilot hole should be created to ensure that the TROD can be installed to the desired depth with space to seal in place. The pilot hole can be completed using power tools such as a hammer drill or hand tools such as a fence-post pounder (fig. 7). Even in sandy environments, it is necessary to pilot a hole to make sure there are no impeding materials (cobbles or boulders) below the surface that may damage or break the PVC.

A 6-foot-long, 1.25-inch-diameter solid steel rock bar is an adequate size to create a pilot hole that will provide enough clearance and allow for the bentonite seal between the PVC and the surrounding sediments. Pipe wrenches are helpful hand tools to remove the rock bar by rotating and lifting. Rotating the rock bar periodically during the install will also ensure that the rock bar can be removed by lifting. If necessary, a fence-post puller or Hi-Lift jack (handyman jack) can be used to extract the rock bar.

\section{Materials needed for installation}

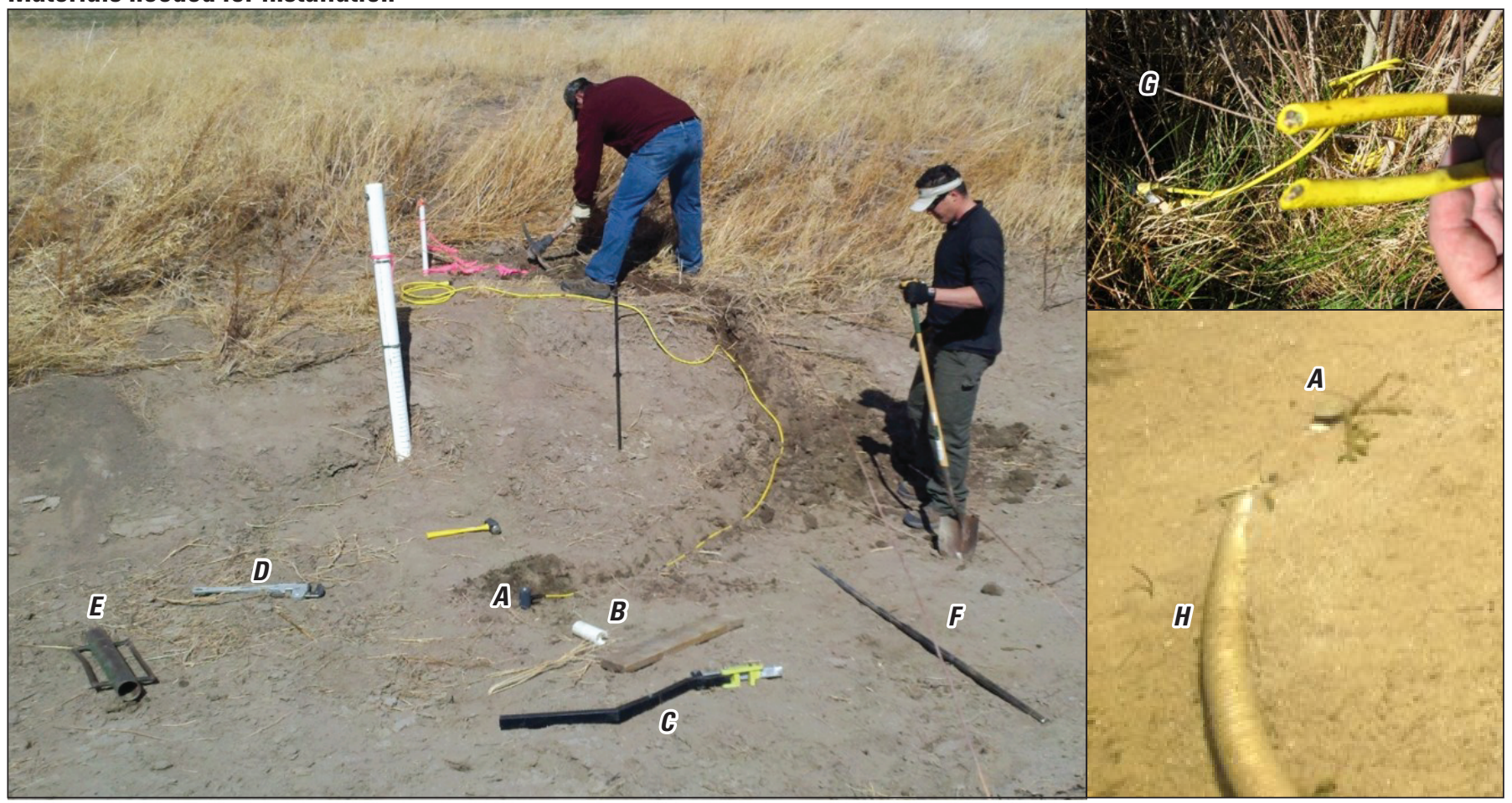

Figure 6. Shown in $(A)$ is a completely installed TROD, $(B)$ installation cap, $(C)$ fence-post puller, $(D)$ extra-long pipe wrench, $(E)$ fencepost driver for installing rock bar used for pilot hole, and $(F)$ rock bar. In environments where damage to the cable $(G)$ is possible (beavers, moles), use $(H)$ electrical conduit or poly pipe to protect the cable. The fence-post puller will help remove the rock bar from the pilot hole. Pipe wrenches are useful for extracting the rock bar from the pilot hole by rotating and lifting. 


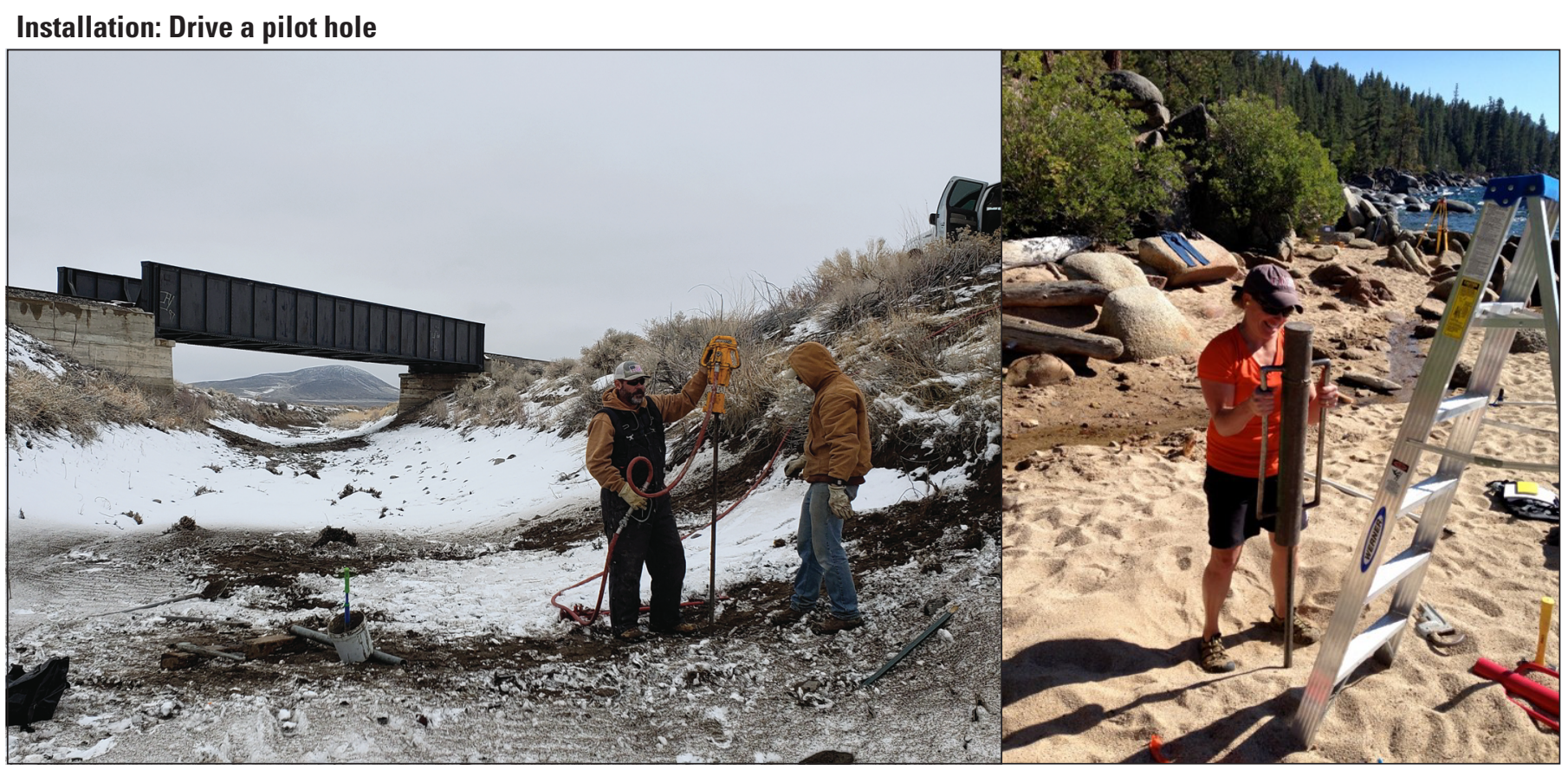

Figure 7. The pilot hole is the most critical aspect to installing the TROD. Installing the TROD without the use of a pilot hole may result in breakage.

\section{Use Bentonite Slurry to Fill Hole}

If the hole stays open following removal of the pilot rod, and dry conditions exists, fill with bentonite slurry using a water plunger (kids water toy or similar; fig. 8). The purpose of the bentonite slurry is to provide a water seal in the annulus between the hole wall and the pipe. This can be done beneath the water surface, but it is quite difficult to dispense bentonite underwater.

Once bentonite has been dispensed into the pilot hole, insert the TROD and push or hammer using the installation cap, extension bar, and post-hole driver to complete the installation (fig. 8A). Once completed, it may be necessary to remove excess bentonite from around the head of the probe. If the extension bar is not used, always hammer on the installation cap to avoid damage to the communication cable or the head bolt. Have one person inspect while hammering to verify the TROD is moving (fig. $8 B$ ). When hammering on the installation cap or the extension rod, use repeated strikes with constant force. The extension bar is used when installing through the water surface. If the pilot hole closes or an obstruction is felt, use discretion hammering on the installation cap. It may take multiple attempts to complete an install.

\section{Removal}

Removing the TROD after a period of monitoring may be difficult to do by hand alone (fig. 9). It may be necessary to dig a small pit around the head to reach below the top, flanged part of the head to attach a rope (fig. 9). A Prusik knot is recommended to prevent slippage of the rope because it tightens as tension increases when using a Hi-Lift jack (handyman jack) to extract the TROD (fig. 9B).

\section{Retrieving Data from TRODs}

Software is available to download data, get real-time temperature readings, mission (start), and download multiple sensors (iButtons) into a single, formatted spreadsheet. Given that the sensors are all connected in series, programming all the sensors to begin recording data at the same start time, time interval, and duration ensures that temperature profile data are consistent. 
Installation: Use bentonite slurry to fill hole
A. TROD with pilot hole
B. Installed TROD into the bentonite-filled pilot hole
C. Use of an extension rod to drive the TROD in moving water

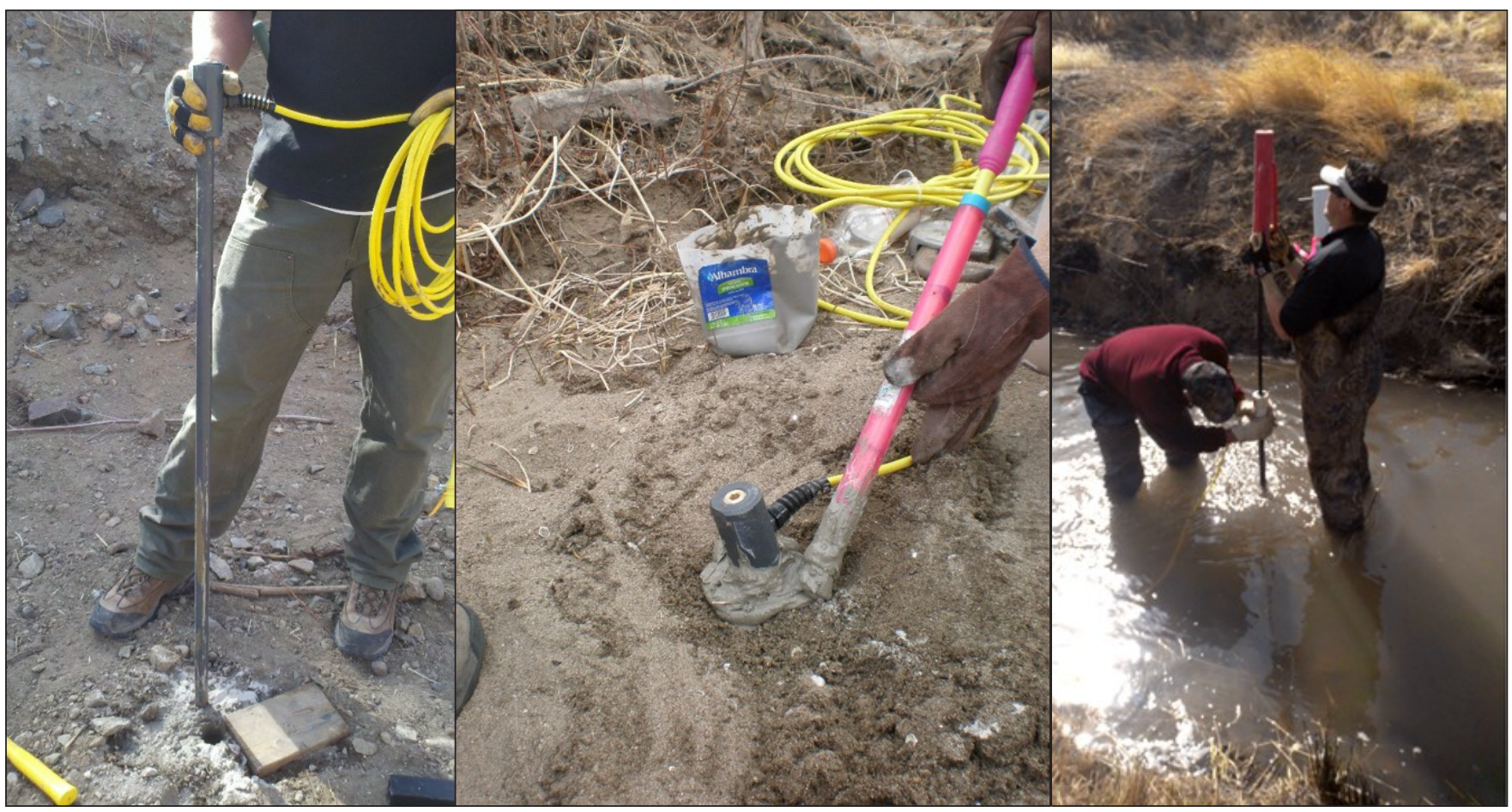

Figure 8. $A$, TROD with pilot hole; $B$, installed TROD into the bentonite-filled pilot hole; and $C$, use of an extension rod to drive the TROD in moving water.

A $\boldsymbol{B}$

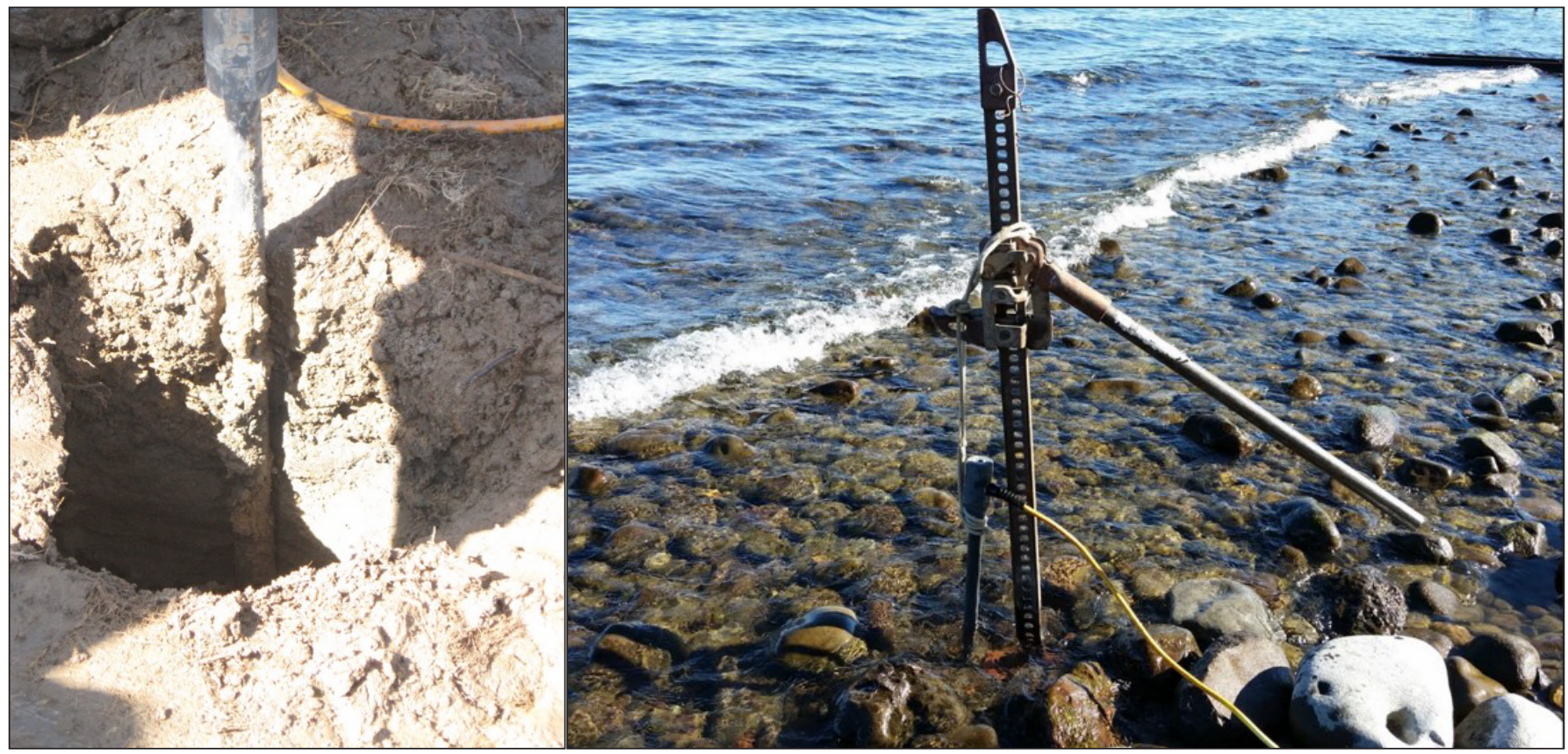

Figure 9. TROD removed by $A$, digging in mud, or $B$, using a Prusik knot and a Hi-Lift jack, shown here in nearshore cobble sediments. 


\section{WeeButton Software}

The WeeButton software was specially designed for the TROD. The software was developed by Alpha Mach and is available for free from https://alphamach.com/ (fig. 10). The WeeButton software allows for starting, stopping, and downloading all sensors at once. The WeeButton output file is a single, formatted Excel file with temperature data organized by sensor depth and serial numbers. The following work flow illustrates the use of the WeeButton software to program and download data.

This WeeButton window allows you to observe in real time the temperatures from each sensor and program all the sensors with one click (fig. 11).

By setting the program with the default "iButton21" tab, the program automatically sets the conditions, such as sample interval, rate, start time, for all sensors. Synchronizing the internal clock to computer time ("synchronize realtime clock") sets a consistent date and time to all sensors (figs. 12-13). Enabling roll over will overwrite data within memory and should be used with caution. This is typically used when data are retrieved prior to roll over.

Ending the set program to retrieve data is done by clicking on the "Stop All Missions" tab. Save the spreadsheet output file by selecting the "Save All Rod" tab and selecting the path location (fig. 14).

The output file generated by WeeButton is an Excel file. The program automatically organizes the data with a date stamp in left-most column and remaining data in the subsequent columns to the right of the date stamp in order from the top of the TROD to the bottom (fig. 15). The serial numbers for each iButton are located as headers for each temperature array.

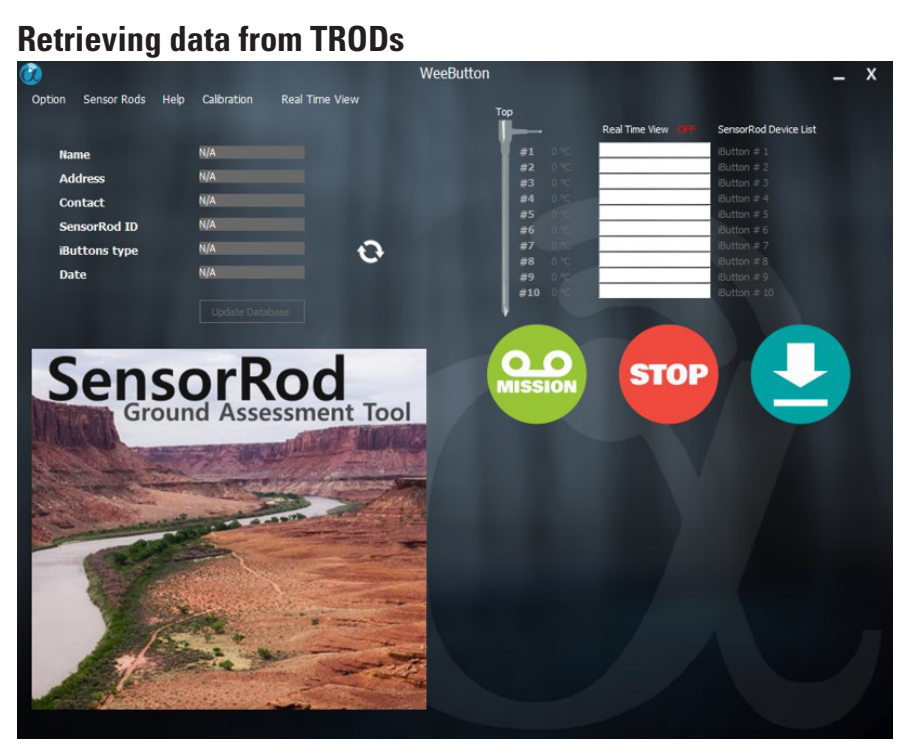

Figure 10. WeeButton software for retrieving data from TRODs (called SensorRods in WeeButton).

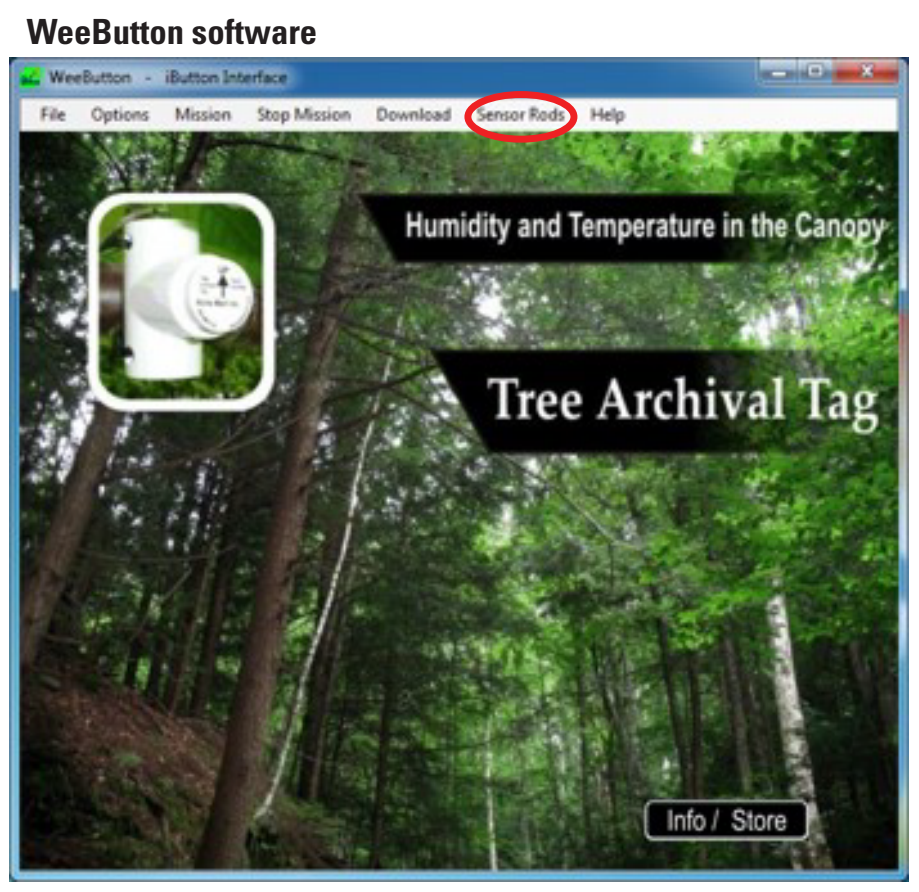

Figure 11. Step 1. Start WeeButton software for use with the temperature profiling probe (TROD). Click on "SensorRods." 


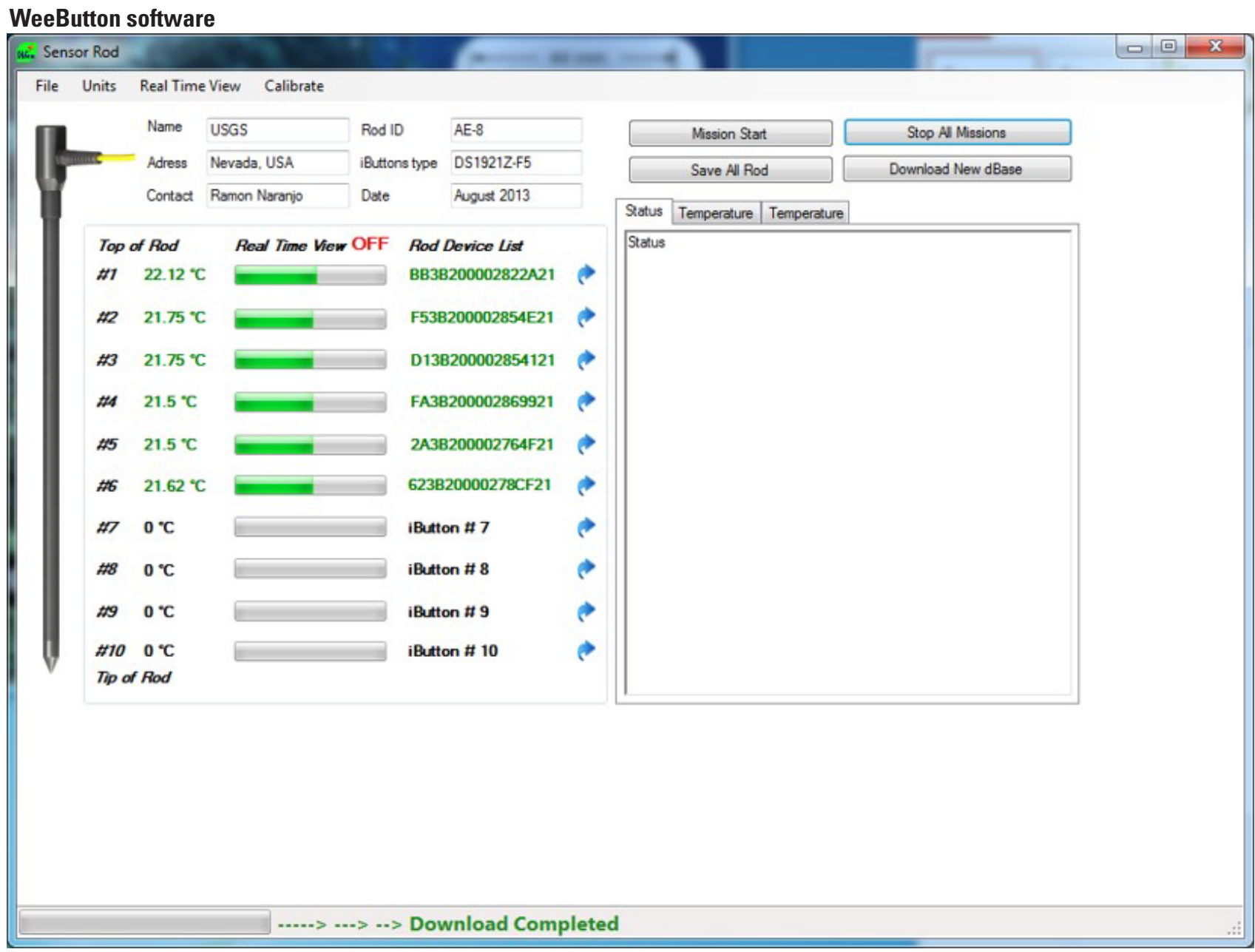

Figure 12. Step 2. Start programs for all iButtons at "Mission Start."

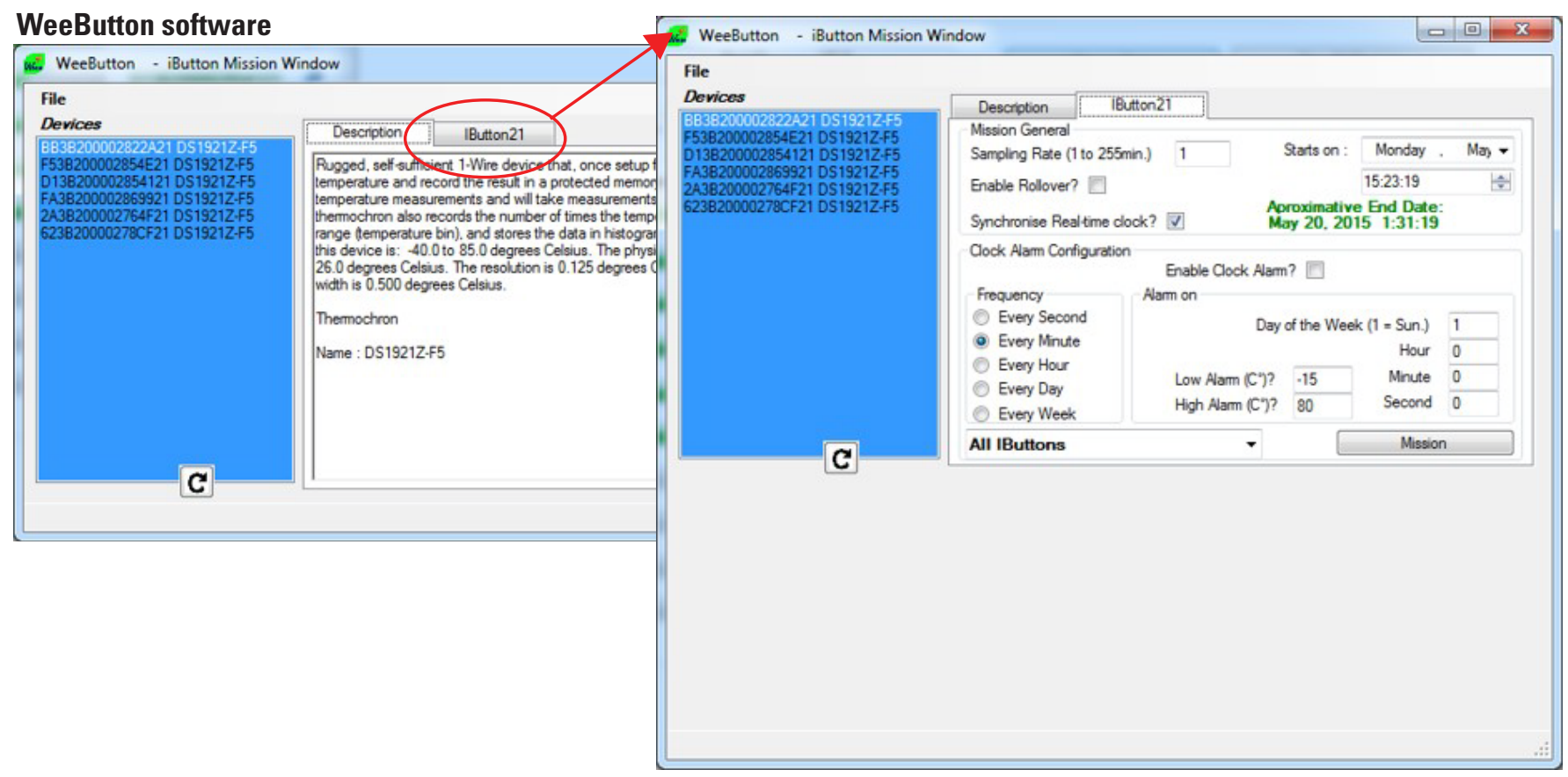

Figure 13. Step 3. Click on "iButton21" (default) tab and set programs for all iButtons. Specify "Sampling Rate," "Starts on," and "Enable Roll Over?" (if applicable) and synchronize to computer time. Careful, you will overwrite data with "Enable Roll Over?" turned on; if left inactive, it will stop recording when memory is full. Click "Mission" to program. 


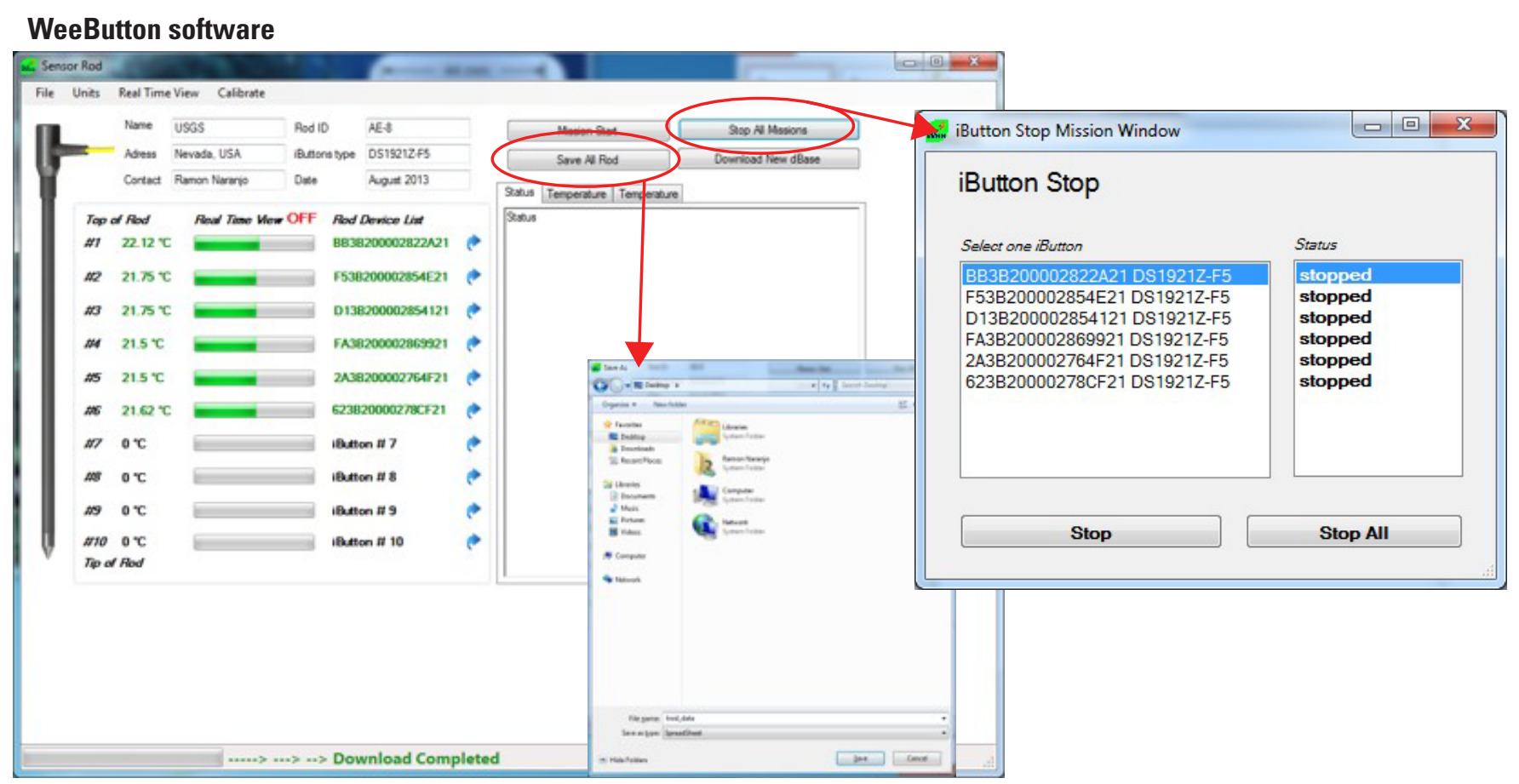

Figure 14. Step 4. To download data, "Stop All" mission and then retrieve data by clicking on "Save All Rod" (default Excel file). If data are set to roll over, it is not necessary to restart program.

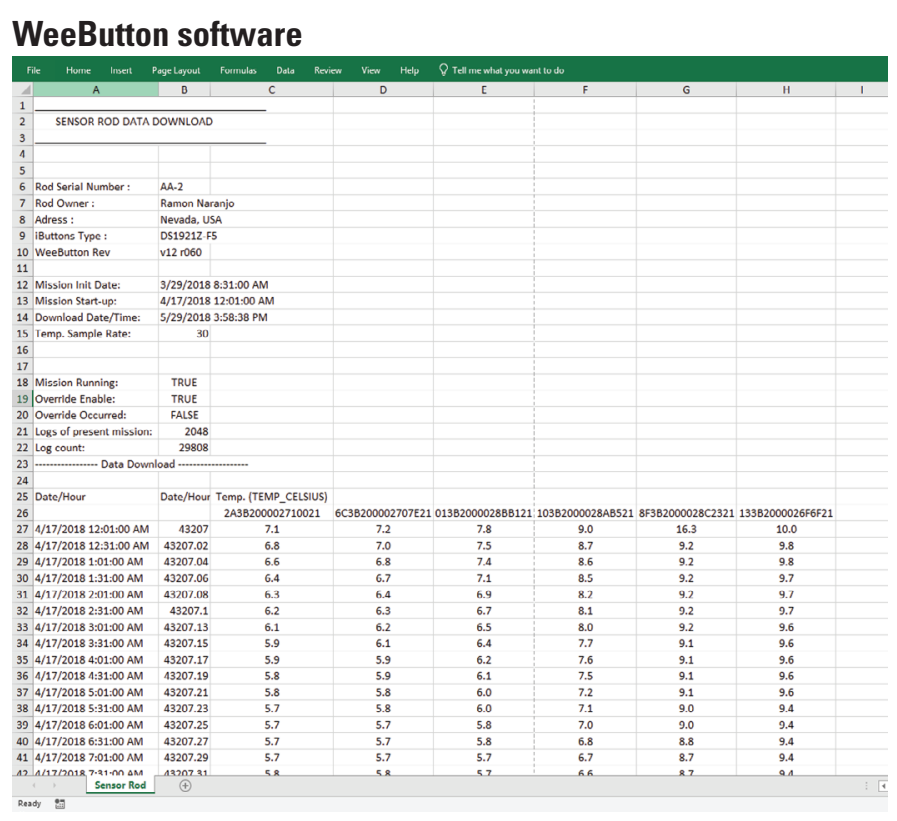

Figure 15. Step 5. WeeButton raw output is provided by sorting the iButtons in order from top to bottom sensor in an Excel file. Serial numbers are helpful to match up with calibration regressions.

\section{Data Integrity}

It is also important to determine the integrity of the data after a couple weeks of monitoring. Problems with the installation can be determined by inspecting the data closely and evaluating temperature with respect to time and depth (temperature envelope). For example, in losing stream conditions, careful inspection of the data can reveal preferential flow along the TROD (fig. 16). A temperature envelope over a 24 -hour period should show high variability near the sediment-water interface and less variability at depth. An inflection point, where temperature data no longer vary with depth, should be easily identifiable. In this example, a properly installed TROD will exhibit phase lag and attenuation with depth, both of which are related to the permeability and thermal properties of sediments. If there is preferential flow down the side of the TROD, there will be no shift in temperature data with the maximum and minimum daily temperatures occurring nearly at the same time. Temperature envelopes will also have consistent variations with depth with no clear inflection point. 

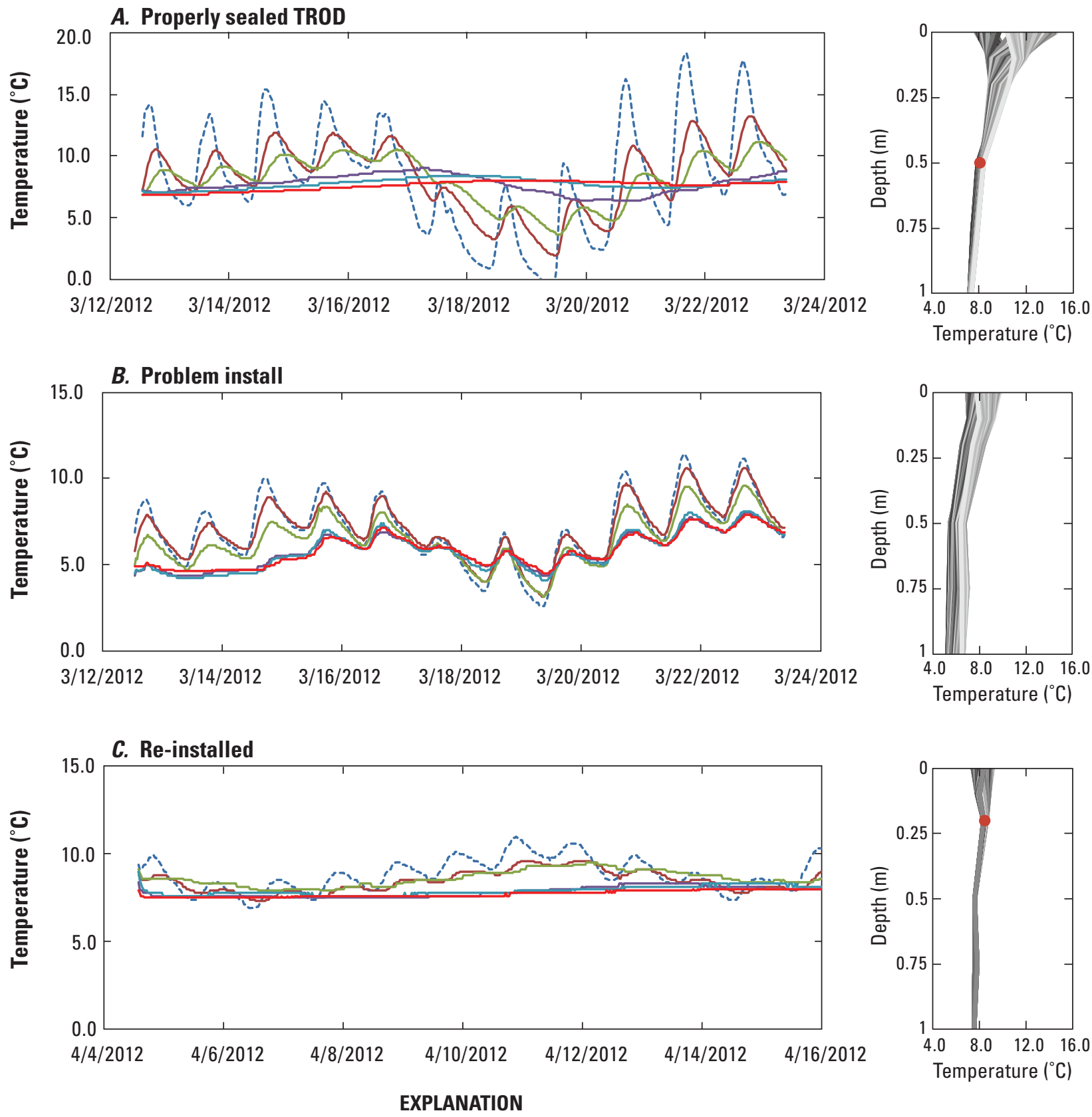

Depth, in meters 0 0.1 0.2 0.5 1

Figure 16. Example data collected from $A$, a site with a properly sealed TROD; $B$, a site with a problematic install; and $C$, re-installed TROD. Red dots show inflection points. The TROD was re-installed and re-sealed owing to preferential flow vertically down the pipe, as indicated by a consistent temperature variation with depth and similar amplitude variations (no clear inflection point). Upon further inspection of the installed TROD, it was evident that the TROD was loose in the pilot hole and sediments did not collapse around the PVC pipe. 


\section{For Applications, Updates, and New Information}

The USGS Nevada Water Science Center is actively using the TROD in a wide range of hydrological investigations. A USGS website dedicated to the TROD is located at https://nevada.usgs.gov/TROD/. Research and development to improve the capability of the TROD is ongoing, as are modifications to the software. Software and TROD updates can be found at https://alphamach.com/.

\section{Selected References}

Constantz, J., Naranjo, R.C., Niswonger, R.G., Allander, K., Neilson, B., Rosenberry, D., Smith, D.W., Rosecrans, C.Z., and Stonestrom, D.A., 2016, Groundwater exchanges near a channelized versus unmodified stream mouth discharging to a subalpine lake: Water Resource Research, v. 52, no. 3, p. 2157-2177, https://doi.org/10.1002/2015WR017013.

Naranjo, R.C., and Turcotte, R., 2015, A new temperature profiling probe for investigating groundwater-surface water interaction: Water Resource Research, v. 51, no. 9, p. 7790-7797, https://doi.org/10.1002/2015WR017574.

Naranjo, R.C., and Smith, D.W., 2016, Quantifying seepage using heat as a tracer in selected irrigation canals, Walker River Basin, Nevada, 2012 and 2013: U.S. Geological Survey Scientific Investigations Report 2016-5133, 169 p., https://doi.org/10.3133/sir20165133.

Niswonger, R., Naranjo, R., Smith, D., Constantz, J., Allander, K., Rosenberry, D., Neilson, B., Rosen, M.R., and Stonestrom, D., 2017, Nutrient processes at the streamlake interface for a channelized versus unmodified stream mouth: Water Resource Research, v. 53, no. 1, p. 237-256, https://doi.org/10.1002/2016WR019538.

Wagner, R.J., Boulger, R.W., Jr., Oblinger, C.J., and Smith, B.A., 2006, Guidelines and standard procedures for continuous water-quality monitors-Station operation, record computation, and data reporting: U.S. Geological Survey Techniques and Methods 1D3, 51 p. +8 attachments, accessed April 10, 2006, at http://pubs.water.usgs.gov/tm1d3. 
For more information concerning the research in this report, contact the Nevada Water Science Center

U.S. Geological Survey

2730 N. Deer Run Road

Carson City, Nevada 95819

https://www.usgs.gov/centers/nv-water 

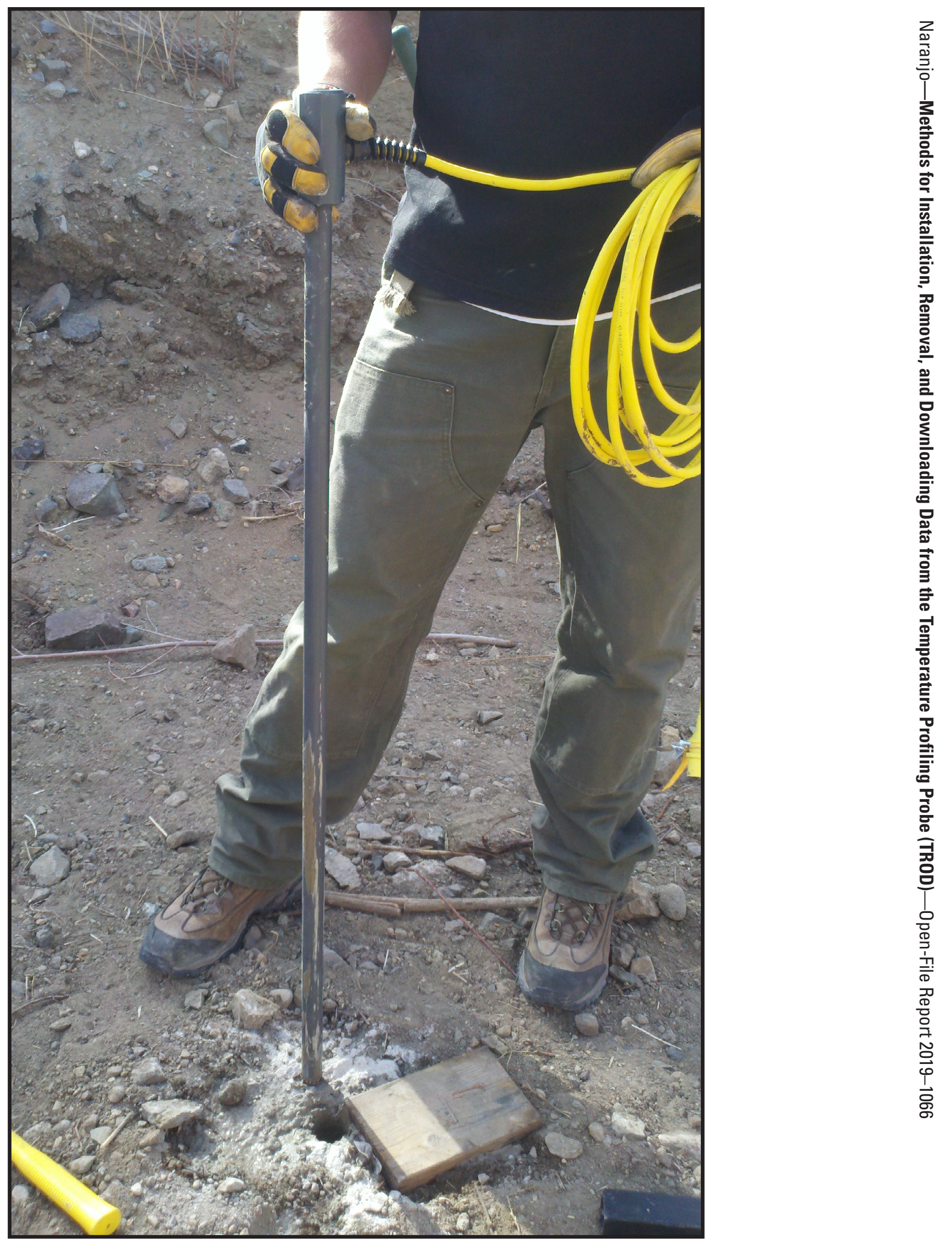